Editorial

\title{
Congenital Infiltrating Lipomatosis of the Face: Recognition and Pathogenesis
}

\author{
Laura Flores-Sarnat ${ }^{1}$ \\ ${ }^{1}$ Division of Pediatric Neurology, Alberta Children's Hospital, \\ University of Calgary Faculty of Medicine, Calgary, Alberta, Canada
}

Neuropediatrics 2012;43:346-348.

Congenital infiltrating lipomatosis of the face (CILF) is a welldefined but underrecognized entity. It occurs as an isolated condition or associated with hemimegalencephaly (HME) and neurocutaneous syndromes (particularly epidermal nevus syndromes), sometimes as part of "total unilateral hypertrophy." Most reports of CILF from the past 20 years attribute the first description to Slavin et al in $1983^{1}$; however, this entity has been described for more than a century under descriptive terms of morphological appearance. It was first described by Beck in 1836 in a case of hemihypertrophy. ${ }^{2}$ The second report, by Friedreich, involved only half of the face. ${ }^{3}$ Another early report was also associated with hemicorporal hypertrophy, probably Proteus syndrome. ${ }^{4}$ Slavin et $\mathrm{al}^{1}$ introduced the term congenital infiltrating lipomatosis of the face, which is appropriate because it more specifically implies the nature of the lesion and has facilitated its recognition. However, "congenital hemifacial lipomatosis" would be more accurate to denote its marked asymmetry. Mild, moderate, and severe (sometimes massive) cases of CILF can be distinguished. Of the three cases reported by Slavin et al, ${ }^{1}$ two were severe and one was mild. The pathologic examination of the lipomatosis of all three cases demonstrated nonencapsulated mature lipocytes with the following criteria: (1) infiltration of adjacent muscle and soft tissue; (2) absence of malignancy; (3) absence of lipoblasts; (4) presence of fibrous elements; (5) increased vessels with unifocally, thickened muscular walls; and (6) increase of nerve bundles with variable size. The lesion was congenital and recurrent after excision in all three patients. Their cases were isolated, and no neurologic or other systemic involvement was referred. Reports of CILF and HME without a concomitant neurocutaneous disorder are rare.

\footnotetext{
*This article is an editorial on "Hemimegalencephaly associated with congenital infiltrating lipomatosis of the face: a case report" by Figà Talamanca et al (Neuropediatrics 2012;43(6):349-352).
}

Infiltrative lipomatosis can occur in many areas of the body. In the case of CILF, the source of this selective and focal lesion in the cheek has been ascribed to the buccal fat pad, initially described as a distinct anatomic structure of the face by Heister in $1727^{5}$ and further delineated histologically as adipose tissue by Bichat in $1801 .^{6}$ Its development was studied by Scammon. ${ }^{7}$

Some of the early reports of CILF were made by dental surgeons. Rushton described in 1937 a 5-year-old boy with severe CILF and with typical clinical features:

...the right side of the face below the eye is very much larger than the left that includes nostril, upper and lower lip, the cheek and the ear. The right side of the face and mouth hang down and protrude and the midline is pushed to the left. The right part of the tongue is much enlarged: its mucous membrane is smooth and lacks papillae. ${ }^{8}$

He also described ipsilateral enlargement of soft palate and alveolar process with early eruption of the teeth. Rowe ${ }^{9}$ described that the hypertrophy of the tongue begins abruptly in the midline.

In this issue, Figà Talamanca et al report the rare case of a male infant with severe (massive) CILF associated with total HME, also severe, in whom many of these clinical features are present. However, no skin or systemic involvement was observed. ${ }^{10}$

The prevalence of CILF is rare but underestimated due, in part, to multiple other terminologies that have been applied to define this entity. Rushton, ${ }^{8}$ described his patient with severe, isolated CILF as "partial gigantism of the face and teeth." Rowe, ${ }^{9}$ a dental surgeon reported four cases of CILF under "hemifacial hypertrophy," including a 69-year-old man, edentulous since 30 years previously. In 1970, Furnas et al described in detail the clinical manifestations of CILF in two children and found the lipomatous nature of this lesion. ${ }^{11}$ Nevertheless, they continued using the nonspecific

Copyright @ 2012 by Thieme Medical Publishers, Inc., 333 Seventh Avenue, New York, NY 10001, USA. Tel: +1(212) 584-4662.
DOI http://dx.doi.org/ 10.1055/s-0032-1330853. ISSN 0174-304X. reprint requests Prof. Laura

Flores-Sarnat, MD, Alberta

Children's Hospital Division of

Pediatric Neurology, 2888

Shaganappi Trail NW, Calgary, AB

T3B 6A8, Canada

(e-mail: Laura.Flores-

Sarnat@albertahealthservices.ca). 
term congenital hypertrophy of the face. However, they addressed the important association with neurocutaneous syndromes. Boltshauser and Navratil ${ }^{12}$ reported an infant who had a facial sebaceous nevus associated with ipsilateral HME and CILF. They described the involvement of cranial bony structures and soft tissues of the face and called this presentation "hemimacrocephaly." Dean et $\mathrm{al}^{13}$ reported three neonates with severe CILF and HME under the designation of "cranial hemihypertrophy." Of which, two neonates had epidermal nevus syndromes. Pavone et al ${ }^{14}$ reviewed 17 patients (4 personal observations) with HME and epidermal nevus syndrome; 9 had CILF. They provided a comprehensive review of the epidermal nevus syndrome and the neurological features and introduced the term "neurologic variant...." Unfortunately, this term is inadequate because of its nonspecificity. The lipomatous nature of the "facial hemihypertrophy" was not specified despite confirmation in one case. Di Rocco et al $^{15}$ reported an infant with severe CILF associated with epidermal nevus syndrome and HME. They described the hemifacial mass as "gigantism of the face." A case of massive CILF and HME was designated as "facial hemihypertrophy." 16 Many reports of "hemifacial hypertrophy" of "hemifacial hyperplasia" correspond to CILF. Chen et al in 2002 found 14 cases (including 1 personal observation) of isolated and associated CILF. ${ }^{17}$ The largest series of CILF included 13 patients: 9 had capillary stain on the cheek, the presence of HME was not mentioned, and RET and PTEN mutations were investigated in 6 children with negative results. ${ }^{18}$ Two interesting cases reported as Proteus syndrome associated with HME are not confirmed as Proteus; however, the evidence of CILF in both patients was not addressed. ${ }^{19}$ In a recent report of two neonates with CLOVES syndrome (congenital lipomatous overgrowth, vascular malformations, epidermal nevi, and scoliosis), both with HME and CILF, only in one neonate was HME recognized, ${ }^{20}$ and CILF was not diagnosed in either. In an other case, fetal magnetic resonance imaging (MRI) showed both anomalies amongst many others. ${ }^{21}$ In a careful review of HME, epilepsy, and surgical treatment, a patient with HME and ipsilateral epidermal nevus showed evident CILF that was not recognized. ${ }^{22}$

In a few reports of hemifacial epidermal nevus and ipsilateral HME, CILF (not severe) was recognized, but erroneously diagnosed as lipoma. I described one of those cases (review by Flores-Sarnat, ${ }^{23}$ Fig. 2 ) and made the observation about the typical presentation with the association of those three conditions.

The first report of a patient with that typical triad was made in 1955 in Heide-a German girl with a left epidermal nevus in the face and neck and a congenital ipsilateral enlargement of the cheek. The cheek mass persisted after surgery. It was reported as a benign "lipom" Thickening of the left lower lip deviated downward, and enlargement of half of the tongue was noted. She also had epilepsy and intellectual disability. HME was confirmed by autopsy. ${ }^{24}$ Unfortunately, Heide was a victim of "active euthanasia" due to her neurological disabilities. The named term "Heide syndrome" for this distinct presentation that often goes unrecognized is thereby justified. ${ }^{25}$ Even in recent years, the problem in many reports of failure to recognize one or two cardinal anomalies of this triad persists. The acknowledgment of Heide syndrome will enable a more definitive and inclusive diagnosis of these patients.

Figà Talamanca et $\mathrm{al}^{10}$ correctly emphasize to investigate HME by neuroimaging in cases of CILF even in the absence of neurological features and provide a detailed description of the multiple and severe anomalies demonstrated by neuroimaging. The use of computed tomography (CT) and MRI facilitate the planning of surgery, and in this patient, it enabled the visualization of anomalies not reported previously. MRI is the preferred method to define the extent of the lipomatous infiltration in muscles (severe in this patient, who also showed severe infiltration of the orbit), which is rarely reported.

Children with severe CILF who undergo surgery pose complex anesthetic management due to unique complications that require expertise and anticipation. ${ }^{26,27}$ Children with moderate ${ }^{28}$ and severe $\operatorname{CILF}^{26,29}$ may present upper airway obstruction, secondary to severe or massive hypertrophy of the ipsilateral palatine tonsil. ${ }^{28,29}$ An infant with massive CILF had unremarkable postoperative course after partial excision of his lesion, but the infant had early regrowth and died 6 months later from cardiopulmonary complications. ${ }^{30}$

Many reports of CILF from the past 25 years do not discuss aspects of embryology and state that the cause of this condition is unknown. By contrast, Figà Talamanca et $\mathrm{al}^{10}$ have addressed the concept of the role of the neural crest. ${ }^{31}$ The genetic basis of CILF, a sporadic disorder, remains unknown. However, it is known that adipose tissue is a neural crest derivative, and this explains the pathogenesis of CILF. The fact that CILF frequently is associated with contiguous bone involvement, often hyperplasia, is further a clear evidence of a neural crest origin because membranous bone derives from neural crest precursors. Most of the craniofacial bones, such as the orbits and cranial vault, including the rostral twothirds of the parietal bone, are membranous and of mesencephalic neural crest origin. The occipital and posterior third of the parietal bone is from paraxial mesoderm, derived from endochondral bone as with the cranial base. In this case, rare findings by CT and MRI are reported: The enlarged left sphenoid wing and foramen rotundum in of the cranial base are not explained by defective neural crest; whereas, the hyperplasia of left orbital, mandibular and zygomatic bones, connective tissue of the tongue, cartilage of the ear, intracranial blood vessels, and the enlarged ophthalmic and maxillary branches of the trigeminal nerve as well as the trigeminal ganglion and fossa are all explained by neural crest defects. $^{32}$

To summarize, the patient reported by Figà Talamanca et a ${ }^{10}$ clearly illustrate that congenital infiltrating lipomatosis can be considered a neurocristopathy. As Bolande stated 20 years after introducing this term, "Neurocristopathy as a pathogenetic concept should continue to be useful as a structural framework for future investigations." ${ }^{33}$ The relation with neurocutaneous syndromes is not surprising, 
both being neurocristopathies. The association with HME might be explained in the future by common genetic pathways. The recent discoveries that the AKT family of genes is the genetic basis of HME (AKT3) $)^{34}$ and Proteus syndrome $(A K T 1)^{35}$ and that de novo somatic mutations of the PI3K-AKT3-mTOR pathway cause HME, ${ }^{36}$ pose the question whether these mutations also may play a role in the pathogenesis of CILF. A genetic approach studying skin biopsies with keratinocytic nevi was successful in demonstrating mutations in FGFR3 and PIK3CA. This example can be extended for the direct study of hyperplastic adipose tissue.

Special caution should be observed in cases of CILF without apparent skin lesions because epidermal nevi or vascular lesions may not be present at birth but appear later. The investigation and management of these children is best accomplished by a multidisciplinary team that includes a dental/maxillofacial surgeon, neurologist, neuroradiologist, neurosurgeon, pathologist, dermatologist, geneticist, and otolaryngologist.

\section{References}

1 Slavin SA, Baker DC, McCarthy JG, Mufarrij A. Congenital infiltrating lipomatosis of the face: clinicopathologic evaluation and treatment. Plast Reconstr Surg 1983;72(2):158-164

2 Beck CJ. Med Annalen von Puchelt. Chelius und Nägele; 1836:S89

3 Friedreich N. Ueber congenitale halbseitige Kopfhypertrophie. Virchows Arch 1863;28:474-481

4 Reissmann C. Further note on a case of unilateral gigantism. Australasian Med Gazette 1904:280-281

5 Heister L. Compendium anatomicum. 3rd ed. G. Creech et G. Schaw; 1727: Altdorf, Guill, Koleshii: 134, table VIII and figs 36-37

6 Bichat X. Anatomie generale appliquee a la physiologie et a la medecine. Paris, France: Brosson Gabon et Cie Libraires; 1801:60

7 Scammon RE. On the development and finer structure of the corpus adiposum buccae. Anat Rec 1919;15:267-287

8 Rushton MA. Partial gigantism of face and teeth. Br Dent J 1937;62:572-578

9 Rowe NH. Hemifacial hypertrophy. Review of the literature and addition of four cases. Oral Surg Oral Med Oral Pathol 1962; 15:572-587

10 Figà Talamanca L, Verdolotti T, Colafati GS, Bernardi B. Hemimegalencephaly associated with congenital Infiltrating lipomatosis of the face: a case report. Neuropediatrics 2012;43(6): 349-352

11 Furnas DW, Soper RT, Nickman NJ, Till DJ. Congenital hemihypertrophy of the face: impersonator of childhood facial tumors. J Pediatr Surg 1970;5(3):344-348

12 Boltshauser E, Navratil F. Organoid nevus syndrome in a neonate with hemimacrocephaly. Neuropadiatrie 1978;9(2):195-196

13 Dean JC, Cole GF, Appleton RE, Burn J, Roberts SA, Donnai D. Cranial hemihypertrophy and neurodevelopmental prognosis. J Med Genet $1990 ; 27(3): 160-164$

14 Pavone L, Curatolo P, Rizzo R, et al. Epidermal nevus syndrome: a neurologic variant with hemimegalencephaly, gyral malformation, mental retardation, seizures, and facial hemihypertrophy. Neurology 1991;41(2(Part 1)266-271

15 Di Rocco F, Novegno F, Tamburrini G, Iannelli A. Hemimegalencephaly involving the cerebellum. Pediatr Neurosurg 2001;35(5): 274-276
16 Ogunbiyi AO, Lagunju I. Nevus sebaceous syndrome with facial hemihypertrophy. Pediatr Dermatol 2007;24(4):428-429

17 Chen CM, Lo LJ, Wong HF. Congenital infiltrating lipomatosis of the face: case report and literature review. Chang Gung Med J 2002;25 (3):194-200

18 Padwa BL, Mulliken JB. Facial infiltrating lipomatosis. Plast Reconstr Surg 2001;108(6):1544-1554

19 Bastos H, da Silva PF, de Albuquerque MA, et al. Proteus syndrome associated with hemimegalencephaly and Ohtahara syndrome: report of two cases. Seizure 2008;17(4): 378-382

20 Gucev ZS, Tasic V, Jancevska A, et al. Congenital lipomatous overgrowth, vascular malformations, and epidermal nevi (CLOVE) syndrome: CNS malformations and seizures may be a component of this disorder. Am J Med Genet A 2008;146A(20): $2688-2690$

21 Fernandez-Pineda I, Fajardo M, Chaudry G, Alomari AI. Perinatal clinical and imaging features of CLOVES syndrome. Pediatr Radiol 2010;40(8):1436-1439

22 Terra-Bustamante VC, Machado HR, Sakamoto AC. Hemimegalencephaly and epilepsy: an overview. J Epilepsy Clin Neurophysiol 2006;12:99-105

23 Flores-Sarnat L. Hemimegalencephaly: part 1. Genetic, clinical, and imaging aspects. J Child Neurol 2002;17(5):373-384, discussion 384

24 Gross H, Uiberrak B. Klinisch-anatomische Befunde bei Hemimegalencephalie; über die Stellung der cerebralen Hyperplasie und des örtlichen Riesenwuchses innerhalb der Phakomatosen. Virchows Arch 1955;327(5):577-589

25 Flores-Sarnat L. Epidermal nevus syndrome. In: Dulac O, Lassonde M, Sarnat HB, eds. Handbook of Clinical Neurology. Vol. 111 (3rd series). Pediatric Neurology. Amsterdam, The Netherlands: Elsevier BV. In press

26 Trapp LD, Lee C, Troutman KC, Simon JE. Anesthetic management of the pediatric patient with multiple congenital anomalies including severe hemifacial hypertrophy. Anesth Prog 1981;28 (6):162-166

27 Diaz JH. Perioperative management of infants with the linear naevus sebaceous syndrome of Jadassohn: a report of two cases. Paediatr Anaesth 2000;10(6):669-673

28 Oktay MF, Topcu I, McKinney A, Turunz V, Aras O. Isolated hemifacial hypertrophy: a case with upper airway obstruction and sensorineural hearing loss. J Laryngol Otol 2006;120(8): 691-693

29 Sculerati N, Jacobs JB. Congenital facial hemihypertrophy: report of a case with airway compromise. Head Neck Surg 1985;8(2): $124-128$

30 Pires Fraga MF, Mello D, Jorge D, Perin LF, Helene A. Congenital infiltrating lipomatosis. J Plast Reconstr Aesthet Surg 2009;62(12): e561-e564

31 Sarnat HB, Flores-Sarnat L. Embryology of the neural crest: its inductive role in the neurocutaneous syndromes. J Child Neurol 2005;20(8):637-643

32 Le Douarin N, Kalcheim C. The Neural Crest. 2nd ed. Cambridge, UK: Cambridge University Press; 1999

33 Bolande RP. Neurocristopathy: its growth and development in 20 years. Pediatr Pathol Lab Med 1997;17(1):1-25

34 Poduri A, Evrony GD, Cai X, et al. Somatic activation of AKT3 causes hemispheric developmental brain malformations. Neuron 2012; 74(1):41-48

35 Lindhurst MJ, Sapp JC, Teer JK, et al. A mosaic activating mutation in AKT1 associated with the Proteus syndrome. N Engl J Med 2011;365(7):611-619

36 Lee JH, Huynh M, Silhavy JL, et al. De novo somatic mutations in components of the PI3K-AKT3-mTOR pathway cause hemimegalencephaly. Nat Genet 2012;44(8):941-945 